Research Article

\title{
Extraction and Characterization of Microfibrillated Cellulose from Discarded Cotton Fibers through Catalyst Preloaded Fenton Oxidation
}

\author{
Xianmeng Xu $(\mathbb{D}$, Ning Lu, Shunmin Wang $(\mathbb{D}$, Mengqi Huang, Shenglong Qu, \\ and Feng Xuan
}

College of Biological and Food Engineering, Bozhou University, Tangwang Road, Bozhou 236000, Anhui, China

Correspondence should be addressed to Shunmin Wang; wangshunmin@126.com

Received 2 March 2021; Accepted 16 July 2021; Published 26 July 2021

Academic Editor: Lingxue Kong

Copyright ( $\odot 2021$ Xianmeng Xu et al. This is an open access article distributed under the Creative Commons Attribution License, which permits unrestricted use, distribution, and reproduction in any medium, provided the original work is properly cited.

\begin{abstract}
With rapid developments in science and technology, mankind is faced with the dual severe challenges of obtaining needed resources and protecting the environment. The need for sustainable development strategies has become a global consensus. As the most abundant biological resource on Earth, cellulose is an inexhaustible, natural, and renewable polymer. Microfibrillated cellulose (MFC) offers the advantages of abundant raw materials, high strength, and good degradability. Simultaneously, MFC prepared from natural materials has high practical significance due to its potential application in nanocomposites. In this study, we reported the preparation of MFCs from discarded cotton with short fibers by a combination of $\mathrm{Fe}^{2+}$ catalyst-preloading Fenton oxidation and a high-pressure homogenization cycle method. Lignin was removed from the discarded cotton with an acetic acid and sodium chlorite mixed solution. Then, the cotton was treated with $\mathrm{NaOH}$ solution to obtain cotton cellulose and oxidized using Fenton oxidation to obtain Fenton-oxidized cotton cellulose. The carboxylic acid content of the oxidized cotton cellulose was $126.87 \mu \mathrm{mol} / \mathrm{g}$, and the zeta potential was $-43.42 \mathrm{mV}$. Then, the Fenton-oxidized cotton cellulose was treated in a high-speed blender under a high-pressure homogenization cycle to obtain the MFC with a yield of $91.58 \%$. Fourier transform infrared spectroscopy (FTIR) indicated that cotton cellulose was effectively oxidized by $\mathrm{Fe}^{2+}$ catalyst-preloading Fenton oxidation. The diameter of the MFC ranged from several nanometers to a few micrometers as determined by scanning electron microscopy (SEM), the crystallinity index ( $\mathrm{CrI}$ ) of the MFC was $83.52 \%$ according to X-ray diffraction (XRD), and the thermal stability of the MFC was slightly reduced compared to cotton cellulose, as seen through thermogravimetric analysis (TGA). The use of catalystpreloading Fenton oxidation technology, based on the principles of microreactors, along with high-pressure homogenization, was a promising technique to prepare MFCs from discarded cotton.
\end{abstract}

\section{Introduction}

Cotton is an important cash crop that plays a key role in economic affairs worldwide [1]. As an excellent natural material, cotton provides the main supply of natural fibers for textile industries and other fields $[2,3]$. The production of cotton fabrics has constantly increased in the past few decades, and necessities made of cotton can be found practically everywhere consumer textile products are sold. The annual production of cotton fibers is approximately 25.43 million tons [2], and, with the rapid increase in the global population, the demand for, and consumption of, cotton is increasing year by year worldwide. In the process of combining cotton to produce fabrics, short fibers that lack the quality to form threads are discarded and piled up [4]. The discarded cotton becomes trash and accumulates in waste dumps. The massive accumulation of discarded cotton is a huge waste of valuable resources, and, more importantly, discarded cotton causes severe environmental pollution. The discarded cotton fiber is mainly comprised of cellulose (approximately 95\%) [5], and cellulose is a homopolymer of $\beta$-1,4-d-glucose molecules linked in a linear chain [6]. Cellulose and cellulose derivatives have been widely used in chemical, biological, and medical industries [7]. Cellulose acetate is an important cellulose derivative, and 
researchers have prepared nanocomposites based on cellulose acetate and cellulose. For example, antibacterial nanocomposites (NC1-NC4) are produced by dispersing $\mathrm{ZnO}$ nanofillers in a cellulose acetate matrix [7]. Nanocomposite membranes (PES-CA-Ag $\mathrm{O}$ ) have been developed by the inclusion of silver oxide in polyethersulfone and cellulose acetate polymers [8]. Cellulose $/ \mathrm{ZrO}_{2}$ nanohybrids have been synthesized by simple growth of $\mathrm{ZrO}_{2}$ on a cellulose matrix [9]. Lastly, chitosan-coated cellulose filter paper has been used as a support for cobalt nanoparticle preparation [10]. These nanocomposites have a variety of desirable antibacterial, catalytic, redox, and toxic organic properties.

Currently, cellulose is also widely used as the source of microfibrillated cellulose (MFC) and nanocellulose. MFCs are a promising natural material because of their biocompatibility, high mechanical strength, large surface area, low density, and excellent optical and mechanical properties. MFCs have been widely used in paper-making, as catalyst carriers, and for biomedical applications and nanocomposites. MFCs have been prepared from cotton waste using hydrothermal reactions [11], phosphotungstic acid [12], alkaline/urea treatment [13], dilute sodium hydroxide, dilute inorganic acids, and so on. MFCs can also be prepared by chemical pretreatment (TEMPO system oxidation, periodate oxidation, carboxymethylation, Fenton oxidation, etc.) combined with a mechanical method, which can help realize the separation of filaments and reduce mechanical properties at the same time $[14,15]$.

Fenton $\left(\mathrm{Fe}^{2+} / \mathrm{H}_{2} \mathrm{O}_{2}\right)$ oxidation technology has the advantages of environmental friendliness, high efficiency, and low cost, and it has recently been widely studied in the field of cellulose and MFC preparation [16]. However, in the traditional Fenton oxidation system, hydrogen peroxide has been left unreacted in the solution before effectively oxidizing the fiber, which leads to an increase in hydrogen peroxide concentration and a decrease in oxidation efficiency. Catalyst-preloading Fenton oxidation technology is the solution based on the principles of microreactors. The "microreactor" consists of a large number of cellulose macromolecules. $\mathrm{FeSO}_{4} \cdot 7 \mathrm{H}_{2} \mathrm{O}$ is used as a catalyst for preloading, $\mathrm{Fe}^{2+}$ is adsorbed by fibers when infiltration occurs, and a complex catalytic system of "Fe ${ }^{2+}+$ cellulose" is formed. Then, the free $\mathrm{Fe}^{2+}$ is removed, and hydrogen peroxide is introduced, so the Fenton reaction is limited in the "microreactor" [17].

Catalyst-preloading Fenton oxidation technology based on the microreactor principle is an effective method of MFC preparation [17], as it can improve the oxidation efficiency and effectively reduce the amount of hydrogen peroxide. Thus, catalyst-preloading Fenton oxidation was performed on discarded cotton, followed by high-pressure homogenization to prepare MFCs. When the $\mathrm{pH}$ value of the Fenton oxidation system was 3.0, the effects of various parameters, such as the $\mathrm{H}_{2} \mathrm{O}_{2}$ dose, $\mathrm{FeSO}_{4} \cdot 7 \mathrm{H}_{2} \mathrm{O}$ dose, reaction temperature, and time, on the Fenton oxidation efficiency were discussed in the production process of MFCs. Furthermore, the MFC was characterized by SEM, FTIR, XRD, and TGA. The results indicated that the use of catalyst-preloading Fenton oxidation technology based on the microreactor principle along with high-pressure homogenization was a promising technique to prepare MFCs from discarded cotton.

\section{Materials and Methods}

2.1. Materials. Cotton with short fibers discarded in industrial processes was used in this study. First, $50.0 \mathrm{ml}$ acetic acid and $60.0 \mathrm{~g}$ sodium chlorite were dissolved in $500 \mathrm{ml}$ of deionized water. The as-supplied discarded cotton $(6.0 \mathrm{~g})$ was uniformly mixed in the solution under continuous stirring for $1 \mathrm{~h}$ at $75.0^{\circ} \mathrm{C}$ to remove lignin, polyphenols, and proteins [18]. Then, the sample was cleaned with deionized water to $\mathrm{pH}$ 7.0. Next, the sample was treated in a solution of $2.0 \% \mathrm{NaOH}(500 \mathrm{ml})$ and stirred for $2 \mathrm{~h}$ at $80^{\circ} \mathrm{C}$. At the end of the process, the reaction was stopped; deionized water was used to clean the sample and reach a $\mathrm{pH}$ of 7.0, and cotton cellulose was then obtained by drying under vacuum at $55^{\circ} \mathrm{C}$ for $12 \mathrm{~h}$.

Sodium hydroxide pellets $(\mathrm{NaOH}), \mathrm{FeSO}_{4} \cdot 7 \mathrm{H}_{2} \mathrm{O}$, and sodium chloride were provided by Tianjin Tianli Chemical Co., Ltd. A solution of $\mathrm{H}_{2} \mathrm{O}_{2}$ (30.0\%) was received from Shanghai Aladdin Biochemical Technology Co., Ltd. All other chemical reagents used in the experiments were of analytical grade. Deionized water was used throughout the experiment.

2.2. Preparation of MFC. MFC was obtained from dry discarded cotton cellulose using the Fenton $\left(\mathrm{Fe}^{2+} / \mathrm{H}_{2} \mathrm{O}_{2}\right)$ oxidation described by Duan and coworkers [17]. First, a certain amount of $\mathrm{FeSO}_{4} \cdot 7 \mathrm{H}_{2} \mathrm{O}$ was dissolved in $300 \mathrm{ml}$ of deionized water. Then, $3.0 \mathrm{~g}$ of dry cotton cellulose was reacted with the solution at a temperature of $30.0^{\circ} \mathrm{C}$ for $60 \mathrm{~min}$ under vigorous stirring. Next, the free $\mathrm{Fe}^{2+}$ was removed by vacuum filtration and pressing, and the complex catalytic system of "Fe ${ }^{2+}+$ cellulose" was formed. Preloaded cotton cellulose was put into a flask, and the concentration of cotton cellulose was adjusted to $25.0 \%$ with deionized water. Then, a certain volume of $\mathrm{H}_{2} \mathrm{O}_{2}$ was added to the flask. The flask was sealed and shaken at a certain temperature in a shaker at $110 \mathrm{r} / \mathrm{min}$. Then, the reaction was stopped, and the product was washed with deionized water until neutral $\mathrm{pH}$ to obtain Fenton-oxidized cotton cellulose.

The cellulose concentration was controlled at $1.0 \mathrm{wt} . \%$. The fibers were treated five times in a high-speed blender at $20000 \mathrm{r} / \mathrm{min}$ for $40 \mathrm{~s}$, and a Fenton-oxidized cotton cellulose suspension was obtained. Lastly, the Fenton-oxidized cotton cellulose suspension was treated twenty times with a highpressure homogenization cycle at $60.0 \mathrm{MPa}$. The MFC suspension was obtained and then stored in a refrigerator at $4.0^{\circ} \mathrm{C}$.

2.3. Zeta Potential and Carboxyl Group Content of Oxidized Cotton Cellulose. The oxidized cotton cellulose samples were diluted to $0.5 \mathrm{wt} . \%$ and dispersed via a magnetic stirrer (120 $\mathrm{r} / \mathrm{min}$ ) for $30 \mathrm{~min}$ at room temperature $\left(25.0^{\circ} \mathrm{C}\right)$ with deionized water as the dispersant. The zeta potential of the oxidized cotton cellulose was measured by direct potentiometric titration. 
To measure the carboxyl group content of the oxidized cotton cellulose, $20.0 \mathrm{ml}$ of oxidized cotton cellulose suspension containing $1.0 \mathrm{wt}$ \% of the oxidized cotton cellulose was mixed with $50.0 \mathrm{ml}$ of $1 \mathrm{mM} \mathrm{NaOH}$ solution and stirred uniformly. Then, the oxidized cotton cellulose solution was titrated with $2 \mathrm{mM} \mathrm{HCl}$ solution, and the carboxylic acid content was calculated using the following equation [19]:

$$
C_{\mathrm{COOH}}=\frac{50 \times C_{1}-V \times C_{2}}{m} \times 10^{3},
$$

where $C_{\mathrm{COOH}}$ is the content of carboxyl groups ( $\left.\mu \mathrm{mol} / \mathrm{g}\right), 50$ is the volume of $\mathrm{NaOH}$ solution $(\mathrm{ml}), C_{1}$ is the concentration of $\mathrm{NaOH}(\mathrm{mol} / \mathrm{L}), V$ is the volume of consumed $\mathrm{HCl}$ solution $(\mathrm{ml}), C_{2}$ is the concentration of $\mathrm{HCl}(\mathrm{mol} / \mathrm{L})$, and $m$ is the weight of the dry sample of oxidized cotton cellulose $(g)$. The final results were calculated from the average of three parallel measurements for error analysis.

2.4. Yield of MFC. The volume of the MFC suspension was brought to precisely $20.0 \mathrm{ml}$, and the dried MFC sample was obtained by freeze-drying the suspension for $48 \mathrm{~h}$. The weight of the dried sample was recorded as $m_{1}$. The yield of MFC was calculated using the following equation:

$$
\operatorname{yield}(\%)=\frac{m_{1}}{20} \times V \times 100 \text {, }
$$

where yield was the yield of MFC, $m_{1}$ was the weight of the dried MFC sample in $20.0 \mathrm{ml}$ of MFC suspension, and $V$ was the total volume of MFC suspension.

\subsection{Characterization of $M F C$}

2.5.1. Fourier Transform Infrared Spectroscopy (FTIR) Analyses. Changes in the chemical structures of the cotton cellulose and MFC samples were investigated by FTIR spectroscopy. Samples were freeze-dried separately and compressed into a thin film tablet before analysis. The samples were ground and mixed with dried potassium bromide $(\mathrm{KBr})$ powder in an agate mortar at a 1:100 ratio. Then, FTIR analysis was conducted using a Prestige-21 instrument (Shimadzu, JPN) in the range of $4000-400 \mathrm{~cm}^{-1}$ at a $4.0 \mathrm{~cm}^{-1}$ resolution.

2.6. Scanning Electron Microscope (SEM) Analyses. The surface morphologies of the cotton cellulose and the MFC were observed using a scanning electron microscope (S-4800, Hitachi, JPN). The freeze-dried samples were fixed in the sample holder with double-sided, gold-plated, conductive adhesive tape and observed at an accelerating voltage of $5.0 \mathrm{kV}$.

2.7. X-Ray Diffractometer (XRD) Analyses. The cotton cellulose and MFC were freeze-dried, and the X-ray diffraction patterns were measured using a D8 Advance X-ray diffractometer (Bruker, GER) with $\mathrm{Cu} \mathrm{Ka}$ radiation at $40 \mathrm{kV}$ and $40 \mathrm{~mA}$. The diffracted radiation was scanned from $5^{\circ}$ to $40^{\circ}(2 \theta)$ with a scanning speed of $2.0^{\circ} / \mathrm{min}$. The crystallinity index $(\mathrm{CrI})$ was calculated from the ratio of the height of the
002 peaks $\left(I_{002}\right)$ to the height of the lowest intensity peak $\left(I_{\mathrm{am}}\right)$, as shown in the following equation [20]:

$$
\mathrm{CrI}=\frac{I_{002}-I_{\mathrm{am}}}{I_{002}} \times 100 \%,
$$

where $I_{002}$ is the maximum intensity peak of the 002 diffraction at a diffraction angle of approximately $2 \theta=22.5^{\circ}$, corresponding to the cellulose crystalline region, and $I_{\mathrm{am}}$ is the cellulose amorphous region of the lowest intensity at a diffraction angle of approximately $2 \theta=19.2^{\circ}$.

2.8. Thermogravimetry Analyses (TGA). The cotton cellulose and the MFC were freeze-dried, and the thermal stability of the samples was tested by a DSC-60A thermogravimetric analyzer (Shimadzu, JPN) in the temperature range of $25.0^{\circ} \mathrm{C}$ to $600.0^{\circ} \mathrm{C}$ under a nitrogen steam with a flow rate of $25.0 \mathrm{ml} /$ min and a heating rate of $20.0^{\circ} \mathrm{C} / \mathrm{min}$. Approximately $4.0 \mathrm{mg}$ of sample was used for the TGA test.

2.9. Statistical Analysis. All data were expressed as their mean \pm SD. Analysis was performed using SAS software ver. 8.1 , and the comparison of means was performed using Duncan's test.

\section{Results and Discussion}

3.1. The Effect of $\mathrm{FeSO}_{4} \cdot 7 \mathrm{H}_{2} \mathrm{O}$ Dosage on Fenton Oxidation Efficiency. In this study, the effect of $\mathrm{FeSO}_{4} \cdot 7 \mathrm{H}_{2} \mathrm{O}$ dosage on the Fenton oxidation efficiency of cotton cellulose was evaluated under the following conditions: $\mathrm{pH}$ of $3.0,25.0 \%$ cotton cellulose concentration, $\mathrm{H}_{2} \mathrm{O}_{2}$ dosage of $0.20 \mathrm{~g} / \mathrm{g}$ dry oxidized cotton cellulose, reaction temperature of $40.0^{\circ} \mathrm{C}$, and reaction time of $150 \mathrm{~min}$. As shown in Figure 1, when the $\mathrm{FeSO}_{4} \cdot 7 \mathrm{H}_{2} \mathrm{O}$ dosage increased from $0.10 \mathrm{~g}$ to $0.90 \mathrm{~g}$, the carboxylic acid content first increased and then decreased. With increasing doses of $\mathrm{FeSO}_{4} \cdot 7 \mathrm{H}_{2} \mathrm{O}, \mathrm{Fe}^{2+}$ acted as a catalyst, and some mass of $\cdot \mathrm{OH}$ was generated by $\mathrm{H}_{2} \mathrm{O}_{2}$. Meanwhile, C2, C3, and C6 of the cotton cellulose were oxidized to aldehyde groups, which are further oxidized into carboxyl groups [21,22]. The accumulation of carboxylic acid reached a maximum of $126.75 \mu \mathrm{mol} / \mathrm{g}$ when the $\mathrm{FeS}$ $\mathrm{O}_{4} \cdot 7 \mathrm{H}_{2} \mathrm{O}$ dosage was $0.70 \mathrm{~g}$. However, when the FeS$\mathrm{O}_{4} \cdot 7 \mathrm{H}_{2} \mathrm{O}$ dosage was increased further, excess $\mathrm{Fe}^{2+}$ was oxidized into $\mathrm{Fe}^{3+}$, the cotton cellulose quality was reduced, and its color changed to yellow. When the $\mathrm{FeSO}_{4} \cdot 7 \mathrm{H}_{2} \mathrm{O}$ dose increased from $0.10 \mathrm{~g}$ to $0.90 \mathrm{~g}$, the zeta potential showed a tendency to decrease initially before leveling off. When the $\mathrm{FeSO}_{4} \cdot 7 \mathrm{H}_{2} \mathrm{O}$ dose was $0.50 \mathrm{~g}$, the absolute value of the zeta potential decreased to $42.89 \mathrm{mV}$. Copper-cotton cellulose and other metal-based cellulose materials have also gained considerable attention due to their high catalytic activity [23]; the hydroxyl groups on the cellulose structure interact electrostatically with copper nanoparticles to form nanocomposites. When hydrogen peroxide is introduced, $\mathrm{Cu}^{2+}$ can also act as a catalyst, and $\cdot \mathrm{OH}$ will be generated by $\mathrm{H}_{2} \mathrm{O}_{2}$. However, compared with $\mathrm{Cu}^{2+}, \mathrm{Fe}^{2+}$ has a greater oxidizing ability and catalytic effect on hydrogen peroxide [24], and 


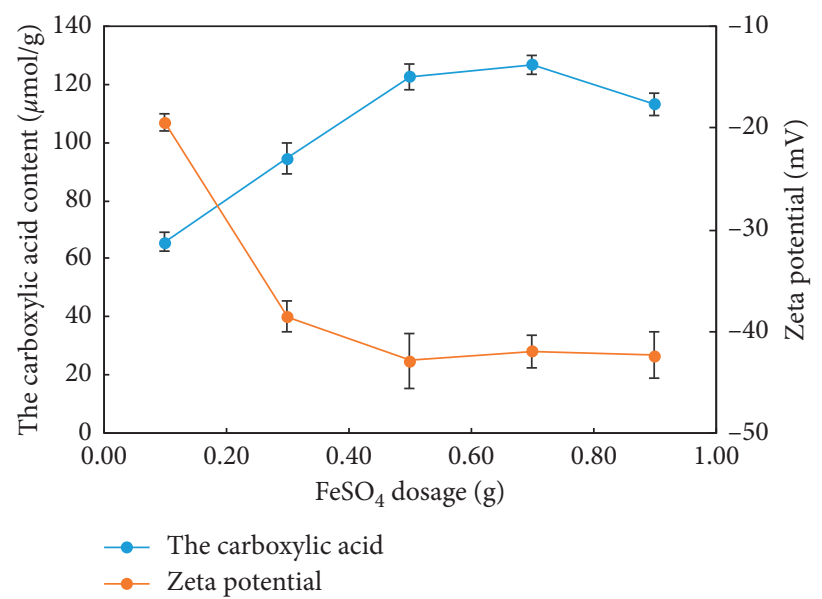

Figure 1: The effect of $\mathrm{FeSO}_{4} \cdot 7 \mathrm{H}_{2} \mathrm{O}$ dosage on Fenton oxidation efficiency.

$\mathrm{Fe}^{2+}$ is more suitable for the Fenton oxidation system to process cotton and obtain MFCs.

\subsection{The Effect of $\mathrm{H}_{2} \mathrm{O}_{2}$ Dosage on Fenton Oxidation} Efficiency. The effect of $\mathrm{H}_{2} \mathrm{O}_{2}$ dosage on the Fenton oxidation efficiency of cotton cellulose was evaluated under the following conditions: $\mathrm{pH}$ of $3.0,25.0 \%$ cotton cellulose concentration, $\mathrm{FeSO}_{4} \cdot 7 \mathrm{H}_{2} \mathrm{O}$ dosage of $0.70 \mathrm{~g}$, reaction temperature of $40.0^{\circ} \mathrm{C}$, and reaction time of $150 \mathrm{~min}$. As shown in Figure 2, when the $\mathrm{H}_{2} \mathrm{O}_{2}$ dosage increased from $0.05 \mathrm{~g} / \mathrm{g}$ dry oxidized cotton cellulose to $0.25 \mathrm{~g} / \mathrm{g}$, the carboxylic acid content first increased and then decreased. Under the catalysis of $\mathrm{Fe}^{2+}, \cdot \mathrm{OH}$ with strong oxidizing properties will be produced by $\mathrm{H}_{2} \mathrm{O}_{2}$, effectively oxidizing the surface of cotton cellulose [25]. The accumulation of carboxylic acid reached a maximum of $124.52 \mu \mathrm{mol} / \mathrm{g}$ when the $\mathrm{H}_{2} \mathrm{O}_{2}$ dosage was $0.20 \mathrm{~g} / \mathrm{g}$. Meanwhile, $\mathrm{H}_{2} \mathrm{O}_{2}$ could release a mass of $\mathrm{H}^{+}$in an aqueous solution, and these $\mathrm{H}^{+}$ions were freely available to interact with the oxygen atoms in the ether linkages of cellulose [26, 27]. The hydrolysis of cotton cellulose was more facile [12]. However, when the $\mathrm{H}_{2} \mathrm{O}_{2}$ dosage was increased further, excess $\mathrm{H}_{2} \mathrm{O}_{2}$ existed in the reaction system, and $\mathrm{OOH}$ with low oxidation potential was produced through a side reaction of $\mathrm{H}_{2} \mathrm{O}_{2}$ and $\cdot \mathrm{OH}$ [28]. Excess $\mathrm{H}_{2} \mathrm{O}_{2}$ also caused ineffective consumption of $\cdot \mathrm{OH}$ because of the reaction $\left(\cdot \mathrm{OH}+\cdot \mathrm{OH} \longrightarrow \mathrm{O}_{2}+\mathrm{H}_{2} \mathrm{O}\right)$ [29], which led to a decrease in the carboxylic acid content of cotton cellulose. When the $\mathrm{H}_{2} \mathrm{O}_{2}$ dosage increased from $0.05 \mathrm{~g} / \mathrm{g}$ to $0.25 \mathrm{~g} / \mathrm{g}$, the zeta potential also showed the trend of decreasing first and then increasing. When the $\mathrm{H}_{2} \mathrm{O}_{2}$ dosage was $0.20 \mathrm{~g} / \mathrm{g}$, the absolute value of the zeta potential decreased to its lowest value, $43.22 \mathrm{mV}$, with the most stable cotton cellulose suspension.

3.3. The Effect of Reaction Temperature on the Fenton Oxidation Efficiency. The effect of reaction temperature on the Fenton oxidation efficiency of cotton cellulose was evaluated under the following conditions: $\mathrm{pH}$ of 3.0, 25.0\% cotton cellulose concentration, $\mathrm{FeSO}_{4} \cdot 7 \mathrm{H}_{2} \mathrm{O}$ dosage of
$0.7 \mathrm{~g}, \mathrm{H}_{2} \mathrm{O}_{2}$ dosage of $0.20 \mathrm{~g} / \mathrm{g}$ dry oxidized cotton cellulose, and a reaction time of $150 \mathrm{~min}$. As shown in Figure 3, with the increase in reaction temperature, the carboxylic acid content initially increased. When the temperature exceeded $40.0^{\circ} \mathrm{C}$, the carboxylic acid content of cotton cellulose decreased; the maximum carboxylic acid content was $122.91 \mu \mathrm{mol} / \mathrm{g}$. A reaction temperature above $40.0^{\circ} \mathrm{C}$ promoted the decomposition of $\mathrm{H}_{2} \mathrm{O}_{2}$ into $\mathrm{H}_{2} \mathrm{O}$ and $\mathrm{O}_{2}$, causing ineffective consumption of $\mathrm{H}_{2} \mathrm{O}_{2}$ [30]. When the reaction temperature increased from $20.0^{\circ} \mathrm{C}$ to $60.0^{\circ} \mathrm{C}$, the zeta potential showed a tendency to first decrease and then increase. When the reaction temperature reached $40.0^{\circ} \mathrm{C}$, the absolute value of the zeta potential was $41.66 \mathrm{mV}$.

3.4. The Effect of Reaction Time on the Fenton Oxidation Efficiency. The reaction time was a nonnegligible factor in the Fenton oxidation efficiency of cotton cellulose. The effect of reaction time on the Fenton oxidation efficiency of cotton cellulose was evaluated under the following conditions: $\mathrm{pH}$ of $3.0,25.0 \%$ cotton cellulose concentration, $\mathrm{FeSO}_{4} \cdot 7 \mathrm{H}_{2} \mathrm{O}$ dosage of $0.70 \mathrm{~g}, \mathrm{H}_{2} \mathrm{O}_{2}$ dosage of $0.20 \mathrm{~g} / \mathrm{g}$ dry oxidized cotton cellulose, and a reaction temperature of $40.0^{\circ} \mathrm{C}$. The experimental results are shown in Figure 4. When the reaction time increased from $30 \mathrm{~min}$ to $150 \mathrm{~min}$, the carboxylic acid content of cotton cellulose increased, reaching a maximum value of $128.31 \mu \mathrm{mol} / \mathrm{g}$ at $150 \mathrm{~min}$, while the zeta potential decreased to an absolute minimum value of $42.48 \mathrm{mV}$ at $120 \mathrm{~min}$.

At the above optimum process conditions $(25.0 \%$ cotton cellulose concentration, a $\mathrm{pH}$ of 3.0 , an FeS$\mathrm{O}_{4} \cdot 7 \mathrm{H}_{2} \mathrm{O}$ dosage of $0.70 \mathrm{~g}$, an $\mathrm{H}_{2} \mathrm{O}_{2}$ dosage of $0.20 \mathrm{~g} / \mathrm{g}$ dry oxidized cotton cellulose, a reaction temperature of $40.0^{\circ} \mathrm{C}$, and a reaction time of $150 \mathrm{~min}$ ), the carboxylic acid content of the cotton cellulose was $126.87 \mu \mathrm{mol} / \mathrm{g}$, and the zeta potential was $-43.42 \mathrm{mV}$ according to a verification experiment. Then, the Fenton-oxidized cotton cellulose was treated in a high-speed blender under highpressure homogenization cycles to obtain MFC. The yield of MFC was $91.58 \%$. 


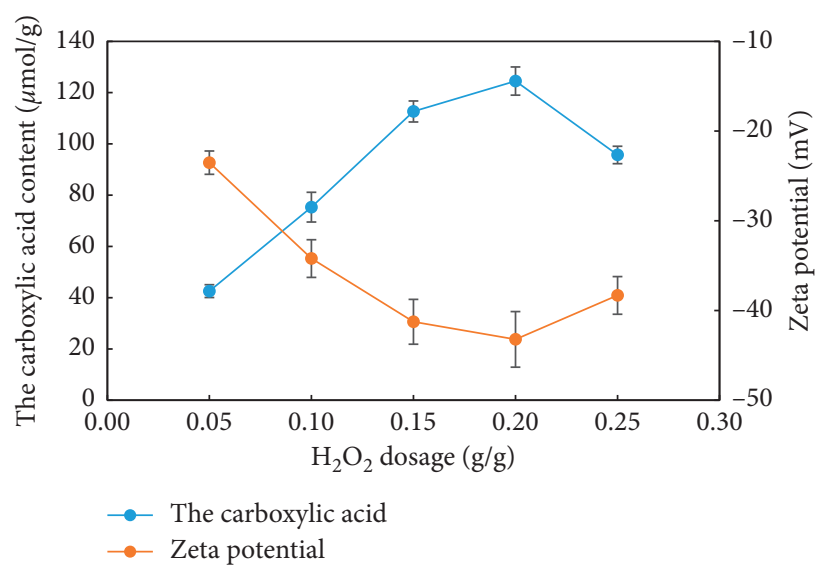

Figure 2: The effect of $\mathrm{H}_{2} \mathrm{O}_{2}$ dosage on Fenton oxidation efficiency.

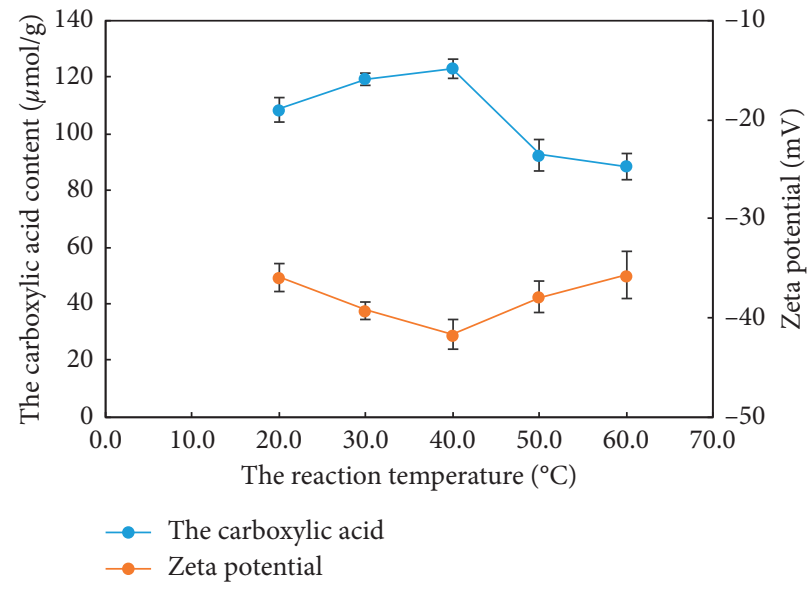

Figure 3: The effect of reaction temperature on the Fenton oxidation efficiency.

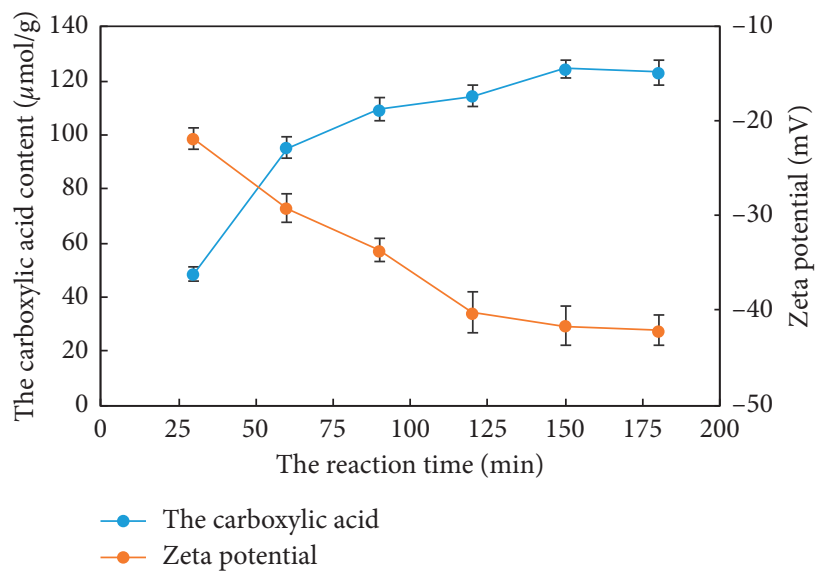

Figure 4: The effect of reaction time on the Fenton oxidation efficiency.

\subsection{Characterization of $M F C$}

3.5.1. FTIR. Infrared spectroscopy works based on the vibrations of atoms in a molecule to be tested. The functional groups present are determined in order to characterize the chemical structure of samples; thus, FTIR has become one of the most important analytical techniques for scientists
[12, 31]. The FTIR spectra of MFC and cotton cellulose are shown in Figure 5. The $2988-3800 \mathrm{~cm}^{-1}$ region was attributed to hydrogen bonds, which were associated with the $-\mathrm{OH}$ stretching vibrations of cellulose $[32,33]$. The band at $2908 \mathrm{~cm}^{-1}$ represented $\mathrm{CH}$ - symmetric stretching vibrations [34]. The band at $1438 \mathrm{~cm}^{-1}$ could be attributed to crystalline absorption [35]. The absorption band at $1356 \mathrm{~cm}^{-1}$ could be 


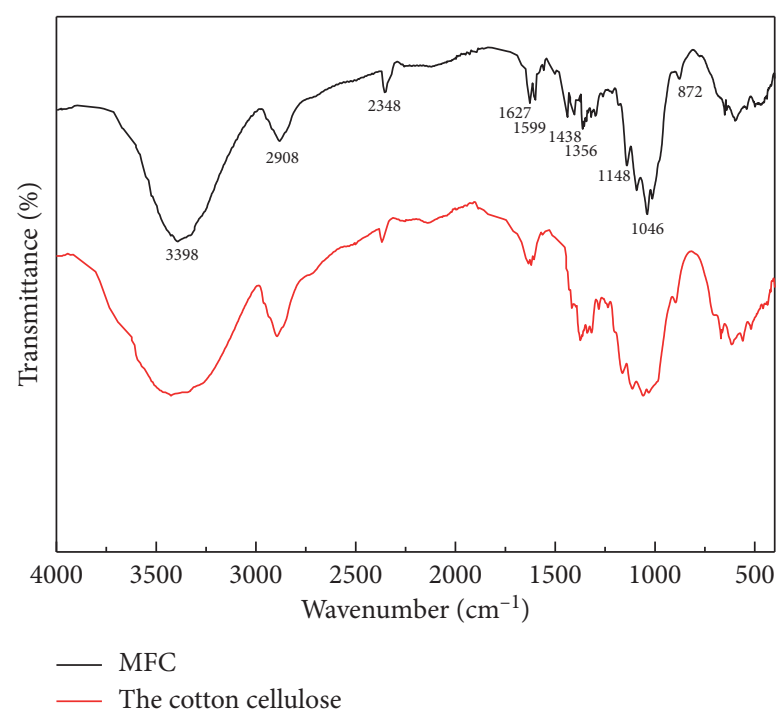

FIGURE 5: FTIR spectra of MFC and cotton cellulose.

attributed to $-\mathrm{OH}$ bending vibrations [36]. The band at $1148 \mathrm{~cm}^{-1}$ was attributed to the $\mathrm{C}-\mathrm{O}-\mathrm{C}$ stretching vibrations of cellulose $[34,37]$. The band at $1046 \mathrm{~cm}^{-1}$ was also attributed to $\mathrm{C}-\mathrm{O}-\mathrm{C}$ stretching vibrations. The absorption band at $872 \mathrm{~cm}^{-1}$ could be ascribed to the $\beta-1,4$-glycosidic bonds in cellulose [12]. The FTIR peaks of MFC and cotton cellulose were similar, so MFC had similar characteristics to cotton cellulose. Compared with cotton cellulose, there were some differences in the FTIR spectra of MFC. The band at $1627 \mathrm{~cm}^{-1}$ of MFC could be attributed to the absorption of carbonyl groups, which were oxidized by $\mathrm{C}-\mathrm{OH}$ groups [38].

3.5.2. SEM. The morphological and structural changes of cotton cellulose after being treated with $\mathrm{Fe}^{2+}$ catalyst-preloading Fenton oxidation and a high-pressure homogenization cycle are shown in Figure 6. Compared to cotton cellulose, the microstructure of MFC changed significantly. The fabric structure of cotton cellulose was destroyed, transforming the cotton cellulose into irregular MFCs. It was found that cotton cellulose had a smooth surface and stiff structure (Figures 6(a) and 6(b)). When subjected to $\mathrm{Fe}^{2+}$ catalyst-preloading Fenton oxidation, the cotton cellulose adsorbed the $\mathrm{Fe}^{2+}$, and a complex catalytic system of " $\mathrm{Fe}^{2+}+$ cellulose" was formed. Then, a mass of $\cdot \mathrm{OH}$ was generated by $\mathrm{H}_{2} \mathrm{O}_{2}$, and the surface of the cotton cellulose was effectively oxidized. The C2, C3, and C6 of the cotton cellulose were oxidized to aldehyde groups. The aldehyde groups were further oxidized into carboxyl groups, and the physical structure of the fiber cell wall was seriously damaged $[22,39,40]$. Then, mechanical treatment with a highpressure homogenization cycle effectively destroyed the firm structure of the cotton cellulose fabric by the disruptive forces of cavitation, turbulence, and shear stress [41]. In addition, the morphology of the fibers changed, and the fiber size decreased. At the same time, the cotton cellulose was sheared into smaller fragments with a decrease in the length and width; the diameter ranged from several nanometers to a few micrometers (Figures 6(c) and 6(d)). The length could reach tens or even hundreds of microns, indicating a high aspect ratio, which provided a performance guarantee for its application in adsorption carriers and reinforcement materials. However, aggregation of the MFC occurred after freeze-drying, and the formation of the aggregate structure was ascribed to growing ice crystals and sublimation during the process of freeze-drying (Figure 6(c)) [42].

3.5.3. XRD. The crystallinity of MFC and cotton cellulose was measured and determined by $\mathrm{X}$-ray diffraction (XRD), the results of which are shown in Figure 7 . The XRD patterns of MFC and cotton cellulose contained two obvious characteristic peaks at $2 \theta=16.2^{\circ}$ and $2 \theta=22.5^{\circ}$, which were attributed to the 110 crystal face and 002 crystal face, respectively. These peaks are characteristic of cellulose I [43], indicating that treatment with $\mathrm{Fe}^{2+}$ catalyst-preloading Fenton oxidation and a high-pressure homogenization cycle did not change the characteristic XRD peaks of cellulose. As shown in Figure 7, the MFC samples had a higher crystallinity $(\mathrm{CrI}=83.52 \%)$ than cotton cellulose $(78.59 \%)$ due to the oxidation and shearing of cotton cellulose by treatment with $\mathrm{Fe}^{2+}$ catalyst-preloading Fenton oxidation and a high-pressure homogenization cycle.

3.5.4. TGA. The TGA and DTG spectra of MFC and cotton cellulose are shown in Figure 8. It was noted that MFC and cotton cellulose illustrated the same thermal degradation trend. MFC and cotton cellulose samples both displayed a small weight drop at temperatures below $100.0^{\circ} \mathrm{C}$ due to retained moisture loss $[13,44]$. In addition, the samples displayed a dramatic weight loss between $290.0^{\circ} \mathrm{C}$ and 


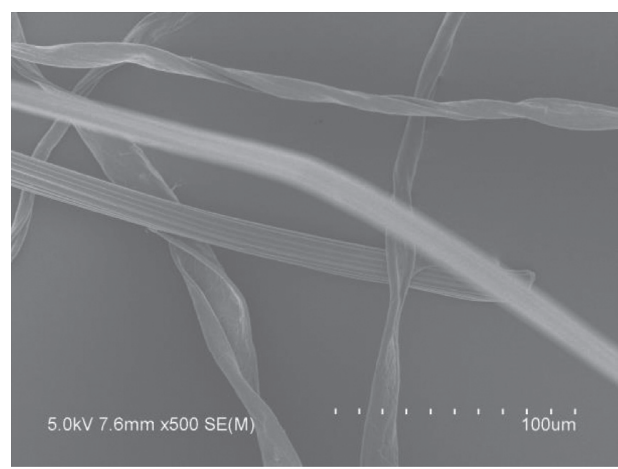

(a)

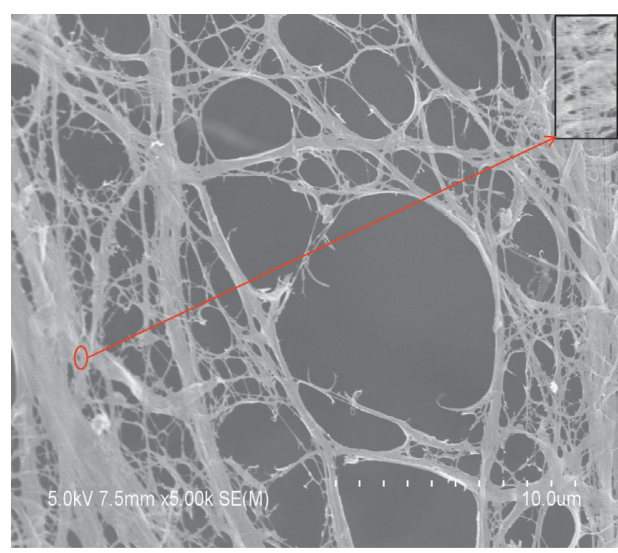

(c)

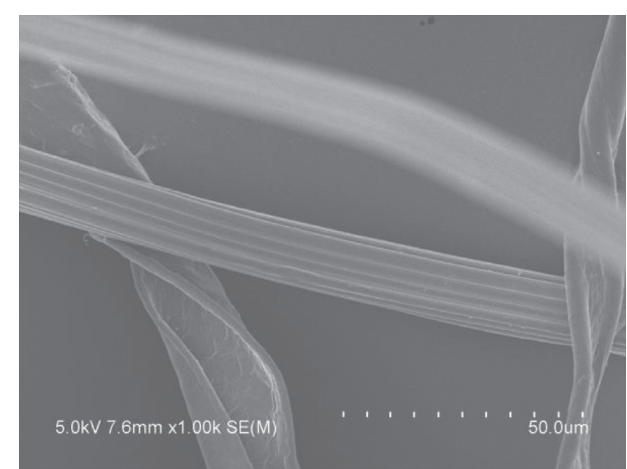

(b)

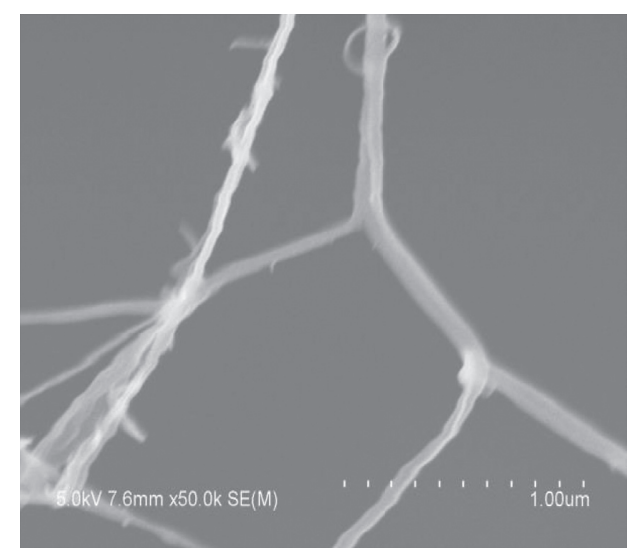

(d)

Figure 6: SEM images of the freeze-dried materials. (a) Cotton cellulose, (b) enlarged image from (a), (c) MFC, and (d) enlarged image from (c).

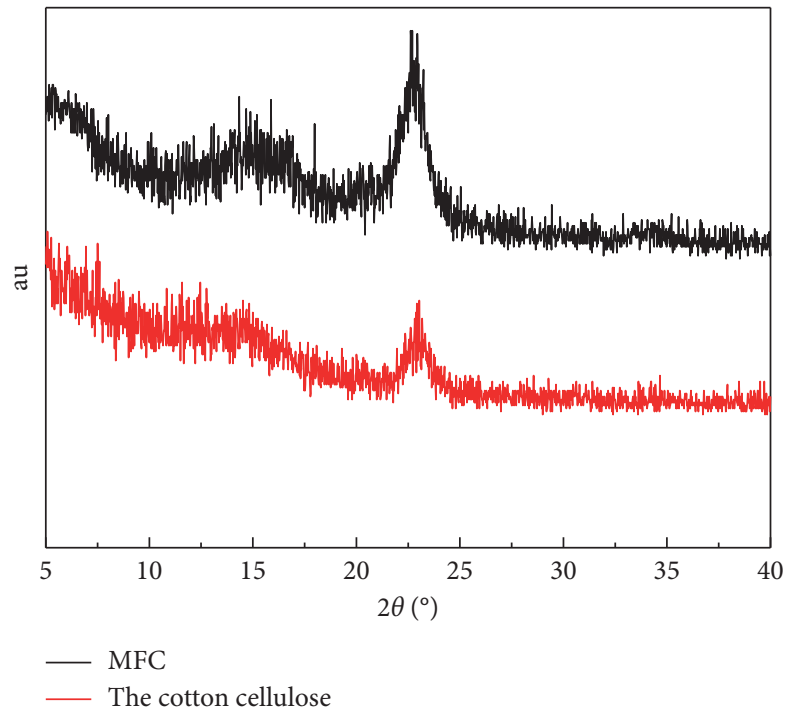

FIGURE 7: XRD patterns of MFC and cotton cellulose.

$370.0^{\circ} \mathrm{C}$ corresponding to cellulose thermal decomposition, including the depolymerization, dehydration, decarboxylation, and decomposition of glycosyl units [12]. We observed that the initial degradation temperature of MFC $\left(222.0^{\circ} \mathrm{C}\right)$ was lower than that of cotton cellulose $\left(264.0^{\circ} \mathrm{C}\right)$. The maximum mass loss rate of MFC also occurred at a lower temperature $\left(342.0^{\circ} \mathrm{C}\right)$ than that of cotton cellulose $\left(369.0^{\circ} \mathrm{C}\right)$. This was because, compared to cotton cellulose, 


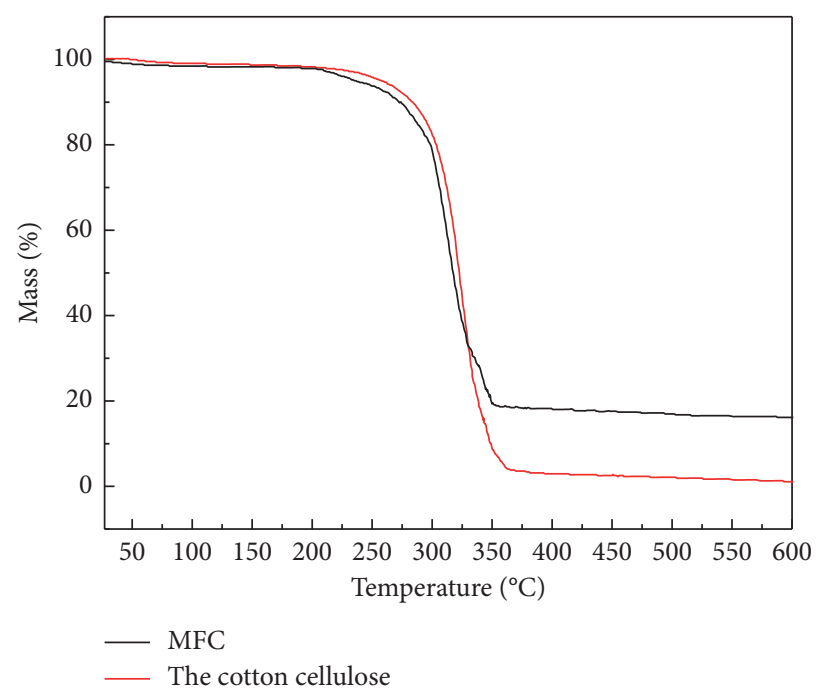

(a)

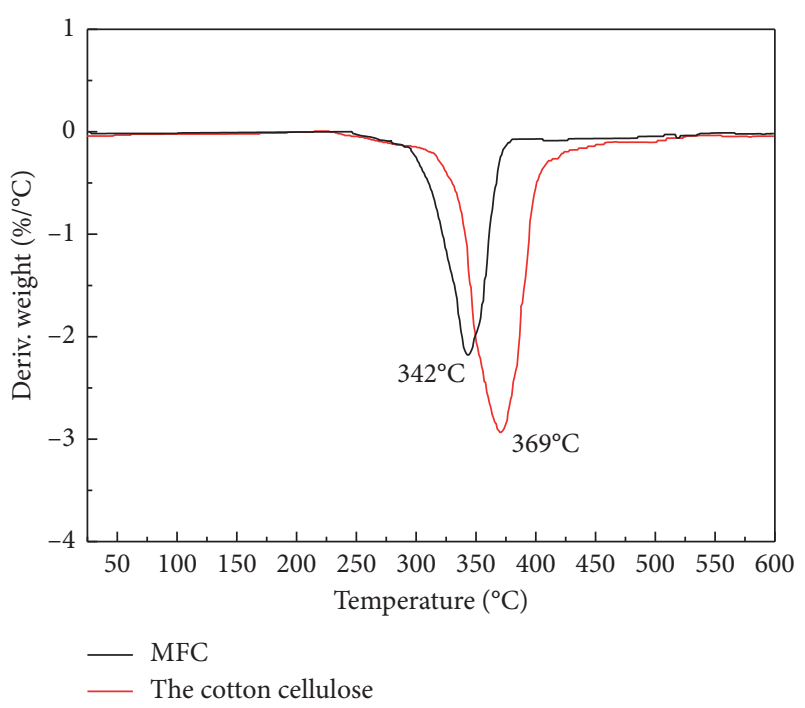

(b)

Figure 8: TG and DTG curves of MFC and cotton cellulose.

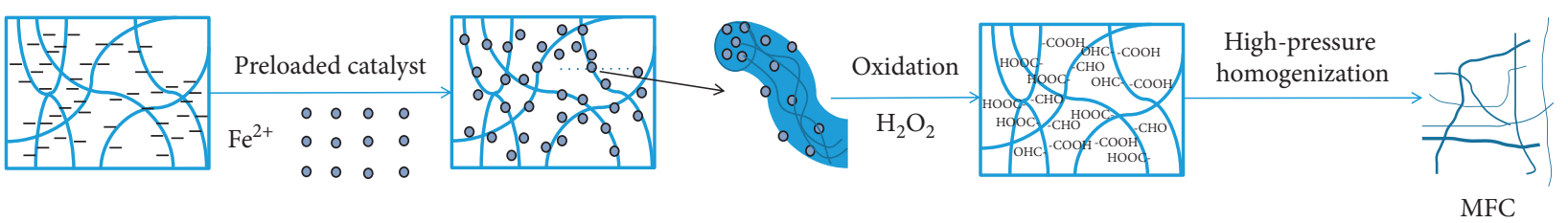

FIGURE 9: The principle of catalyst-preloading Fenton oxidation technology based on a microreactor for MFC preparation.

the particle size of MFC decreased, the specific surface area increased, and the thermal stability decreased [45]. When the temperature was greater than $360.0^{\circ} \mathrm{C}$, ashing of MFC and cotton cellulose occurred; the char content of MFC was lower because of the higher crystallinity [46].

3.6. Principle of Catalyst-Preloading Fenton Oxidation Technology Based on Microreactors. The principle of catalystpreloading Fenton oxidation technology based on a microreactor for MFC preparation is shown in Figure 9. The surface of cotton cellulose is electronegative, and $\mathrm{Fe}^{2+}$ can be effectively adsorbed by it. The "microreactor" consists of a large number of cellulose macromolecules. $\mathrm{FeSO}_{4} \cdot 7 \mathrm{H}_{2} \mathrm{O}$ is used as a catalyst for preloading, $\mathrm{Fe}^{2+}$ is adsorbed by fibers when preloading occurs, and a complex catalytic system of " $\mathrm{Fe}^{2+}+$ cellulose" is formed. Then, the free $\mathrm{Fe}^{2+}$ is removed, and hydrogen peroxide is introduced, so the Fenton reaction is limited in the "microreactor." A mass of $\cdot \mathrm{OH}$ is generated by $\mathrm{H}_{2} \mathrm{O}_{2}$ when $\mathrm{H}_{2} \mathrm{O}_{2}$ is introduced, and the surface of cotton cellulose is effectively oxidized. C2, C3, and C6 of cotton cellulose are oxidized into aldehyde groups. The aldehyde groups are then further oxidized into carboxyl groups, and the physical structure of the fiber cell wall is seriously damaged. At the same time, the $\beta-1,4$-glycosidic bond of cellulose is cleaved by $\cdot \mathrm{OH}$. Then, mechanical treatment with a high-pressure homogenization cycle can effectively destroy the firm structure of the cotton cellulose fabric by the disruptive forces of cavitation, turbulence, and shear effects. Cotton cellulose is sheared into smaller fragments with a decrease in length and width; the diameter ranges from several nanometers to a few micrometers, and the length can reach tens or even hundreds of microns. Finally, the MFC is obtained.

\section{Conclusions}

(1) An effective method was developed for the preparation of MFCs from discarded cotton fibers by a combination of $\mathrm{Fe}^{2+}$ catalyst-preloading Fenton oxidation and a high-pressure homogenization cycle method.

(2) An MFC was obtained from dry discarded cotton cellulose by Fenton $\left(\mathrm{Fe}^{2+} / \mathrm{H}_{2} \mathrm{O}_{2}\right)$ oxidation technology. In this process, $\mathrm{C} 2, \mathrm{C} 3$, and $\mathrm{C} 6$ of the cotton cellulose were oxidized into carboxyl groups, and the $\beta-1,4-$ glycosidic bond of the cotton cellulose was cleaved.

(3) Preloading the Fenton oxidation system with the $\mathrm{Fe}^{2+}$ catalyst could significantly increase the content of carboxyl groups and reduce the zeta potential of the cotton cellulose, which favored the preparation of MFCs.

\section{Data Availability}

The data used to support the findings of this study are available from the corresponding author upon request. 


\section{Conflicts of Interest}

The authors declare that there are no conflicts of interest regarding the publication of this $s$.

\section{Acknowledgments}

The authors are grateful for the support of the Anhui Natural Science Foundation of China (1808085MC93) and the Food Processing Technology Discipline Team of Bozhou University (BYZXKTD201802).

\section{References}

[1] Y. Zhang, Y. Zhang, G. Liu et al., "Nitric oxide increases the biomass and lint yield of field-grown cotton under temporary waterlogging through physiological and molecular regulation," Field Crops Research, vol. 261, Article ID 107989, 2021.

[2] N. Byrne, R. De Silva, Y. Ma, H. Sixta, and M. Hummel, "Enhanced stabilization of cellulose-lignin hybrid filaments for carbon fiber production," Cellulose, vol. 25, no. 1, pp. 723-733, 2018.

[3] D. H. Fockink, M. A. C. Maceno, and L. P. Ramos, "Production of cellulosic ethanol from cotton processing residues after pretreatment with dilute sodium hydroxide and enzymatic hydrolysis," Bioresource Technology, vol. 187, pp. 91-96, 2015.

[4] N. H. N. Do, V. T. Tran, Q. B. M. Tran et al., "Recycling of pineapple leaf and cotton waste fibers into heat-insulating and flexible cellulose aerogel composites," Journal of Polymers And the Environment, vol. 29, no. 4, pp. 1112-1121, 2020.

[5] J. Li, Z. Song, D. Li, S. Shang, and Y. Guo, "Cotton cellulose nanofiber-reinforced high density polyethylene composites prepared with two different pretreatment methods," Industrial Crops and Products, vol. 59, pp. 318-328, 2014.

[6] J. H. O. d. Nascimento, R. F. Luz, F. M. F. Galvão et al., "Extraction and characterization of cellulosic nanowhisker obtained from discarded cotton fibers," Materials Today: Proceedings, vol. 2, no. 1, pp. 1-7, 2015.

[7] S. B. Khan, K. A. Alamry, E. N. Bifari et al., "Assessment of antibacterial cellulose nanocomposites for water permeability and salt rejection," Journal of Industrial and Engineering Chemistry, vol. 24, pp. 266-275, 2015.

[8] S. Gul, Z. A. Rehan, S. A. Khan et al., "Antibacterial PES-CAAg2O nanocomposite supported $\mathrm{Cu}$ nanoparticles membrane toward ultrafiltration, BSA rejection and reduction of nitrophenol," Journal of Molecular Liquids, vol. 230, pp. 616-624, 2017.

[9] S. B. Khan, K. A. Alamry, H. M. Marwani, A. M. Asiri, and M. M. Rahman, "Synthesis and environmental applications of cellulose/ZrO2 nanohybrid as a selective adsorbent for nickel ion," Composites Part B: Engineering, vol. 50, pp. 253-258, 2013.

[10] T. Kamal, S. B. Khan, S. Haider, Y. G. Alghamdi, and A. M. Asiri, "Thin layer chitosan-coated cellulose filter paper as substrate for immobilization of catalytic cobalt nanoparticles," International Journal of Biological Macromolecules, vol. 104, pp. 56-62, 2017.

[11] S. Shi, M. Zhang, C. Ling, W. Hou, and Z. Yan, "Extraction and characterization of microcrystalline cellulose from waste cotton fabrics via hydrothermal method," Waste Management, vol. 82, pp. 139-146, 2018.

[12] W. Hou, C. Ling, S. Shi, and Z. Yan, "Preparation and characterization of microcrystalline cellulose from waste cotton fabrics by using phosphotungstic acid," International Journal of Biological Macromolecules, vol. 123, pp. 363-368, 2019.

[13] W. Liu, S. Liu, T. Liu, T. Liu, J. Zhang, and H. Liu, "Ecofriendly post-consumer cotton waste recycling for regenerated cellulose fibers," Carbohydrate Polymers, vol. 206, pp. 141148, 2019.

[14] H. P. S. Abdul Khalil, Y. Davoudpour, M. N. Islam et al., "Production and modification of nanofibrillated cellulose using various mechanical processes: a review," Carbohydrate Polymers, vol. 99, pp. 649-665, 2014.

[15] L. Brinchi, F. Cotana, E. Fortunati, and J. M. Kenny, "Production of nanocrystalline cellulose from lignocellulosic biomass: technology and applications," Carbohydrate Polymers, vol. 94, no. 1, pp. 154-169, 2013.

[16] P. Hellström, A. Heijnesson-Hultén, M. Paulsson, H. Håkansson, and U. Germgård, "The effect of Fenton chemistry on the properties of microfibrillated cellulose," Cellulose, vol. 21, no. 3, pp. 1489-1503, 2014.

[17] L. J. Duan, Y. Duan, W. Ma, and Q. Li, "Preparation of microfibrillated cellulose through catalyst preloaded fenton oxidation," China Pulp and Paper, vol. 39, no. 1, pp. 9-16, 2020.

[18] J. Xu, E. F. Krietemeyer, V. M. Boddu, S. X. Liu, and W.-C. Liu, "Production and characterization of cellulose nanofibril (CNF) from agricultural waste corn stover," Carbohydrate Polymers, vol. 192, pp. 202-207, 2018.

[19] F. T. Seta, X. An, L. Liu et al., "Preparation and characterization of high yield cellulose nanocrystals (CNC) derived from ball mill pretreatment and maleic acid hydrolysis," Carbohydrate Polymers, vol. 234, Article ID 115942, 2020.

[20] L. Segal, J. J. Creely, A. E. Martin, and C. M. Conrad, "An empirical method for estimating the degree of crystallinity of native cellulose using the X-ray diffractometer," Textile Research Journal, vol. 29, no. 10, pp. 786-794, 1959.

[21] D. F. Guay, B. J. W. Cole, R. C. Fort et al., "Mechanisms of oxidative degradation of carbohydrates during oxygen delignification. II. reaction of photochemically generated hydroxyl radicals with methyl $\beta$-cellobioside," Journal of Wood Chemistry and Technology, vol. 21, no. 1, pp. 67-79, 2001.

[22] K. Michalska, K. Miazek, L. Krzystek, and S. Ledakowicz, "Influence of pretreatment with Fenton's reagent on biogas production and methane yield from lignocellulosic biomass," Bioresource Technology, vol. 119, pp. 72-78, 2012.

[23] S. B. Khan, M. S. J. Khan, T. Kamal, A. M. Asiri, and E. M. Bakhsh, "Polymer supported metallic nanoparticles as a solid catalyst for the removal of organic pollutants," Cellulose, vol. 27, no. 10, pp. 5907-5921, 2020.

[24] J. Zhao, J. J. Yang, and J. Ma, "Degradation of 2, 4, 6-trichlorophenol by copper ion enhanced Fenton reaction," Journal of Harbin Institute of Technology, vol. 45, no. 12, pp. 22-25, 2013.

[25] L. Pan, L. J. Duan, R. R. Liu, L. Zhang, and Q. Li, "Fenton oxidation treatment of fiber surface of unbleached kraft Pulp," China Pulp and Paper, vol. 38, no. 8, pp. 8-13, 2019.

[26] P. L. Dhepe and A. Fukuoka, "Cellulose conversion under heterogeneous catalysis," ChemSusChem, vol. 1, no. 12, pp. 969-975, 2008.

[27] J. Tian, J. Wang, S. Zhao, C. Jiang, X. Zhang, and X. Wang, "Hydrolysis of cellulose by the heteropoly acid H3PW12O40," Cellulose, vol. 17, no. 3, pp. 587-594, 2010.

[28] W. G. Barb, J. H. Baxendale, P. George, and K. R. Hargrave, "Reactions of ferrous and ferric ions with hydrogen peroxide," Nature, vol. 163, no. 4148, pp. 692-694, 1949. 
[29] J.-H. Sun, S.-H. Shi, Y.-F. Lee, and S.-P. Sun, "Fenton oxidative decolorization of the azo dye Direct Blue 15 in aqueous solution," Chemical Engineering Journal, vol. 155, no. 3, pp. 680-683, 2009.

[30] F. J. Rivas, F. J. Beltrán, J. Frades, and P. Buxeda, “Oxidation of p-hydroxybenzoic acid by Fenton's reagent," Water Research, vol. 35, no. 2, pp. 387-396, 2001.

[31] T. Theivasanthi, F. L. Anne Christma, A. J. Toyin, S. C. B. Gopinath, and R. Ravichandran, "Synthesis and characterization of cotton fiber-based nanocellulose," International Journal of Biological Macromolecules, vol. 109, pp. 832-836, 2018.

[32] K. C. C. d. C. Benini, H. J. C. Voorwald, M. O. H. Cioffi, M. C. Rezende, and V. Arantes, "Preparation of nanocellulose from Imperata brasiliensis grass using Taguchi method," Carbohydrate Polymers, vol. 192, pp. 337-346, 2018.

[33] J. Wang, J. Xu, S. Zhu et al., "Preparation of nanocellulose in high yield via chemi-mechanical synergy," Carbohydrate Polymers, vol. 251, p. 117094, 2021.

[34] M. Aguayo, A. Fernández Pérez, G. Reyes et al., "Isolation and characterization of cellulose nanocrystals from rejected fibers originated in the kraft pulping process," Polymers, vol. 10, no. 10, Article ID 1145, 2018.

[35] Q. Lu, L. Lu, Y. Li, and B. Huang, "Facile manufacture of cellulose nanoparticles in high yields by efficient cleavage of hydrogen bonds via mechanochemical synergy," Cellulose, vol. 26, no. 13-14, pp. 7741-7751, 2019.

[36] K. Leppänen, S. Andersson, M. Torkkeli, M. Knaapila, N. Kotelnikova, and R. Serimaa, "Structure of cellulose and microcrystalline cellulose from various wood species, cotton and flax studied by X-ray scattering," Cellulose, vol. 16, no. 6, pp. 999-1015, 2009.

[37] Q. L. Lu, Z. H. Cai, F. C. Lin, L. R. Tang, S. Q. Wang, and B. Huang, "Extraction of cellulose nanocrystals with a high yield of $88 \%$ by simultaneous mechanochemical activation and phosphotungstic acid hydrolysis," ACS Sustainable Chemistry \& Engineering, vol. 4, no. 4, pp. 2165-2172, 2016.

[38] R. D. Kale, P. S. Bansal, and V. G. Gorade, "Extraction of microcrystalline cellulose from cotton sliver and its comparison with commercial microcrystalline cellulose," Journal of Polymers and the Environment, vol. 26, no. 1, pp. 355-364, 2018.

[39] A. Isogai and Y. Zhou, "Diverse nanocelluloses prepared from TEMPO-oxidized wood cellulose fibers: nanonetworks, nanofibers, and nanocrystals," Current Opinion in Solid State \& Materials Science, vol. 23, no. 2, pp. 101-106, 2019.

[40] S. H. Osong, S. Norgren, and P. Engstrand, "Processing of wood-based microfibrillated cellulose and nanofibrillated cellulose, and applications relating to papermaking: a review," Cellulose, vol. 23, no. 1, pp. 93-123, 2015.

[41] R. A. Ilyas, S. M. Sapuan, M. R. Ishak, and E. S. Zainudin, "Sugar palm nanofibrillated cellulose (Arenga pinnata (Wurmb.) Merr): effect of cycles on their yield, physicchemical, morphological and thermal behavior," International Journal of Biological Macromolecules, vol. 123, no. 15, pp. 379-388, 2019.

[42] X. Miao, J. Lin, F. Tian, X. Li, F. Bian, and J. Wang, "Cellulose nanofibrils extracted from the byproduct of cotton plant," Carbohydrate Polymers, vol. 136, pp. 841-850, 2016.

[43] J. Lu, S. L. Shi, R. N. Yang, M. H. Niu, and W. J. Song, "Modification of reed cellulose microstructure and IT change in enzymatic hydrolysis of reed pulp," Transactions of China Pulp and Paper, vol. 20, no. 2, pp. 85-90, 2005.
[44] X. Y. Tan, S. B. Abd Hamid, and C. W. Lai, "Preparation of high crystallinity cellulose nanocrystals (CNCs) by ionic liquid solvolysis," Biomass and Bioenergy, vol. 81, pp. 584-591, 2015.

[45] H. Fukuzumi, T. Saito, Y. Okita, and A. Isogai, "Thermal stabilization of TEMPO-oxidized cellulose," Polymer Degradation and Stability, vol. 95, no. 9, pp. 1502-1508, 2010.

[46] A. Basch and M. Lewin, "The influence of fine structure on the flame retardance of cellulose," Textile Research Journal, vol. 45, no. 3, pp. 246-250, 1975. 